\title{
Relative Control and Management Philosophy
}

\author{
Che-Wei Chang
}

\section{Introduction}

Silicon wafers for the semiconductor industry are extremely complex materials with characteristics such as high purity levels, crystallographic perfection, precise mechanical tolerances, complicating efforts to effectively monitor process stability and control quality for individual product types. Material of silicon wafer can be doped with more than 12 kinds of dopants, such as B, C, N, Al, Si, $\mathrm{Sb}$ and others. Currently, the sizes of the firm's products are 4-, 5-, 6-, 8- and $12-$ inch. Considering dopants and sizes, and each kind of product has different attributes according to which, 7 12 minutes are required to slice a piece of wafer. About 2 minutes are required to inspect the quality of a piece of wafer. A wafer can be easily broken during inspection, because of its thinness and brittleness (Lin et al., 2002). Moreover, slicing is a kind of cutting technique that has difficulty in yielding the required precision. Three scenarios will incur damage on the work piece: (1) inaccurately estimating the precision of the slicing machine, (2) engineers set parameters and change the type of material and (3) inconsistently controlling the wafer quality by applying the sampling method owing to the small batch size of wafer slices in the production model.

Consequently, given unstable yields of synchronously multiple quality characteristics are unstable or drifting accuracy of wire saw machines, inspectors must consider employing machine control and monitoring measures. Five synchronously occurring precision quality characteristics, namely thickness (THK), bow, warp, total thickness variation (TTV), center thickness (CTRTHK) and total indicator reading (TIR) must be simultaneously inspected using automatic testing equipment (ASTM F534, 1995; ASTM F657, 1995; Takeshi, 1998). Those multiple quality characteristics destabilize the slicing. The case firm used quantitative methods, such as process capability indices (PCIs) and statistical process control (SPC) charts, are severely limited in monitoring slicing problems (Lin et al., 2002).

This chapter proposes relative control and management philosophy that in- 
volving three stages to explore slicing problems and enhance slicing quality and process. The first stage, applies focus groups procedure that can explore an engineer's knowledge and expertise. Organizations can effectively use focus groups to create knowledge of stable processes, optimal settings and quality control. Interactive discussions indicate that the focus groups can enhance productivity and effectiveness of decision either by accelerating the decision process or by elevating the quality of the resulting decisions. Moreover, the proposed procedure allows an engineer to rapidly adjust a manufacturing system to eliminate related phenomenon and enhance slicing quality and process capability (Lin et al., 2004). The second stage, applies grey situation decisionmaking (GSDM) is used to screen the worst quality characteristic from the synchronously occurred multiple quality characteristics to monitor the process. Then the exponential weighted moving average (EWMA) control chart is presented to demonstrate and verify the feasibility and effectiveness of proposed discussions. The third stage, applies the Chinese philosophy of yin and yang to illustrate wafer slicing quality, and provides decision makers with philosophical thoughts for balancing the simultaneous consideration of various factors (Lin et al., 2005). Furthermore, to increase process yield and accurately forecast next wafer slice quality, grey forecasting is applied to constantly and closely monitor slicing machine drift and quality control.

\section{Methodology}

\subsection{Focus Groups}

Focus groups are discussion groups brought together to share perceptions on a defined area of interest to generate knowledge and hypotheses, opinions and attitudes to evaluate commercial ventures, ideas, or the assessment of needs is indispensable. Typically eight to twelve participants are conducted by a skilled moderator who introduces the topic and encourages the group to discuss the topic among themselves. Participants are experts on the topic, since the topic is what they think, feel, or do. A discussion guide directs the discussion through topics in an expected order. The moderator guides conversation gently through each topic until that part of the discussion has unproductive, and may return to later if reemerges in a different context. While allowing the moderator to probe and clarify implied or unclear meanings, this flexibility also allows participants to raise important issues and nuances, which research- 
ers often do not foresee. Focus groups rely on the dynamics of group interaction to reveal participants' similarities and differences of opinion (Krueger and Casey, 2000; Morgan, 1997). Participants of relatively homogeneous focus groups have the opportunity to stimulate, support and build on each other's ideas on the topic. Consequently, focus groups reduce the changes of making errors in creating survey questions and, hence improve validity.

Group interaction, spontaneity and sincerity, peer support, descriptive depth, and the opportunity for unanticipated issues to arise - can effectively enable focus groups to create relevance to stable the slicing process, optimal settings and raising the slicing yield. Furthermore, this relatively non-threatening group setting is a cost-effective and efficient means of learning about and elucidating different processes unstable problems by confronting and overcoming difficulties in communication. Focus groups are used in this study to provide some insight into what experiential engineers and their professional knowledge to find slicing problems easier, particularly in terms of information and advice, and the reasons why.

\subsection{Grey Situation Decision-Making and Its Algorithm}

Grey situation decision-making (GSDM) provides a procedure to deal with one event that involves multiple situations in the same event and choose the best or the worst situation what they occur. The definition and algorithm of the method are as follows (Deng, 2003; Lin, et al., 2002).

Definition 1. Let $a_{i}, i=1,2, \ldots, m$ be the sample screening events and $b_{j}, j=1,2, \ldots, n$ be the countermeasures of the multiple quality characteristics in the process. Then, $a_{i}$ and $b_{j}$, are referred to as a combined event, $S_{i j}$, also called a "Situation" and represented as

$$
S_{i j}=\left(a_{i}, b_{j}\right)
$$

Definition 2. Evaluating a criterion for the effectiveness of multiple quality characteristics is called "Target".

Definition 3. If $S_{i j}=\left(a_{i}, b_{j}\right)$ is a situation, then let $\mathrm{p}$ represent the number of 
target. Using the countermeasure, $b_{j}$, which relates to the sample screening event, $a_{i}$, the effectiveness of $a_{i}$ and $b_{j}$, is written as, $E_{i j}^{p}$. Let $\mathrm{M}$ be a mapping, $M\left(E_{i j}^{p}\right)=R_{i j}^{p}$, where $R_{i j}^{p}$ is the value of the mapping between $E_{i j}^{p}$ and $E_{i j}^{p}$, and is an element of $E^{p}$. Let $X^{+}$be positive space. If M satisfied, (1) $M\left(E_{i j}^{p}\right)=R_{i j}^{p} \in R^{p}$ and $R_{i j}^{p} \in[0,1]$ and (2) $R_{i j}^{p} \in X^{+}$, then $\mathrm{M}$ can be called the mapping effectiveness measurement. The properties of $\mathrm{M}$ are as follows.

(1) The upper-bound effective measuring target of $M$ is "higher-the-better." That is

$$
R_{i j}^{p}=\frac{E_{i j}^{p}}{\max _{i} E_{i j}^{p}}
$$

(2) The lower-bound effective measuring target of $\mathrm{M}$ is "lower-the-better." That is

$$
R_{i j}^{p}=\frac{\min _{i} E_{i j}^{p}}{E_{i j}^{p}}
$$

(3) The moderate effective measuring target of $\mathrm{M}$ is "target-is-the-best." That is

$$
R_{i j}^{p}=\frac{\min _{i}\left\{E_{i j}^{p}, E_{0}^{p}\right\}}{\max _{i}\left\{E_{i j}^{p}, E_{0}^{p}\right\}}
$$

Where

$E_{0}^{p}=\frac{1}{n} \sum_{i=1}^{n} E_{i j}^{p}$;

$i$ is the index of sample, and $j$ is the index of the countermeasure for quality characteristics. 
Definition 4. Let the situation, $S_{i j} \mathrm{~S}$, have a measuring target for $\mathrm{n}$ quality characteristics. If the mapping of $E_{i j}^{p}$ is $M\left(E_{i j}^{p}\right)=R_{i j}^{p}$, then $R_{i j}^{1}, R_{i j}^{2}, \ldots, R_{i j}^{n}$ exist; therefore, the synthetic effective measuring of $R_{i j}^{p}$ for one of the quality characteristics is,

$$
R_{i j}^{\Sigma}=\frac{1}{n} \sum_{p=1}^{n} R_{i j}^{p}
$$

Consider n countermeasures, $b_{1}, b_{2}, \ldots, b_{n}$, to deal with for the sample screening event, ${ }_{i}$. Associated mapping synthetic effective measuring vectors, $R_{i}^{\Sigma}$, exist and can be expressed as,

$$
R_{i}^{\Sigma}=\left[R_{i 1}^{\Sigma}, R_{i 1}^{\Sigma}, \ldots, R_{i n}^{\Sigma}\right]
$$

Definition 5. Let $R_{i}^{\Sigma}$ be the synthetic effective measuring vector of $a_{i}$, expressed as, $R_{i}^{\Sigma}=\left[R_{i 1}^{\Sigma}, R_{i 2}^{\Sigma}, \ldots, R_{i n}^{\Sigma}\right]$. If $R_{i j}^{\Sigma^{*}}$ satisfies the following condition,

$$
{ }_{k} R_{i j}^{\Sigma^{*}}=\max _{j}{ }_{k} R_{i j}^{\Sigma}, \quad j \in J=\{1,2, \ldots, n\}
$$

then $S_{i j}^{*}=\left(a_{i}, b_{j}^{*}\right)$ is "satisfied situations"; $b_{j}^{*}$ is the satisfied countermeasure of the quality characteristic of sample screening event, $a_{i}$, and $R_{i j}^{\Sigma^{*}}$ is the best situation of the satisfied situation.

\subsection{Chinese Philosophy - Relative Management and Control}

Einstein (1920) and Laozi state that the world contains no absolutes. Laozi is one of the most influential philosophers during the past 2500 years of Chinese civilization, and in the US the New York Times once chose Laozi as one of the greatest authors of all time (Laozi and Roberts, 2004). Laozi's book, the Dao De Jing, which describes around 5000 Chinese characteristics, described all things 
as originating from the "Way," which is present within all things in the universe. Laozi saw all things as relative. Einstein is one of the most influential physicists in the 20th Century's greatest minds. In 1929, TIME noted in a cover story that "Albert Einstein's theories have altered human existence not at all." In the relativity propounded by Einstein, everything is relative. Specifically, speed, mass, space and time are all subjective. Nor are age, motion or the movements of the planets capable of being objectively measured rather they are judged according to the whim of the observer.

Laozi's book (Laozi and Roberts, 2004), the Dao De Jing, based on the idea that the world contains no absolutes. Laozi saw all things as relative. Notably, management issues are also relative rather than absolute. Figure 1 displays a yin and yang symbol that has been modified to apply to main factors and noise factors. This chapter applies the concept of yin and yang to quality management. The main blocks of color on the yin and yang symbols represent the major effects of decision factors influencing slicing quality. Meanwhile, the small circles of opposite color represent the noise factors affecting decision factors.

The curve symbolizes the constant change in the balance between yin and yang. The above demonstrates the belief that there are no absolutes: nothing is ever entirely yin or yang, but rather a balance always exists between these two forces, just as with time cycles; that is, the process moves in a never-ending cycle characterized by "departing, becoming distant and returning." Consequently, the law of yin and yang involves a balance between yin and yang and an integration of the positive and the negative, light and dark, hot and cold drives all change in the world and provides the life force in the universe. From a directional perspective, Laozi's philosophical thought is focused on balance and continual change. Yin and yang are dependent opposites that must maintain a constant balance.

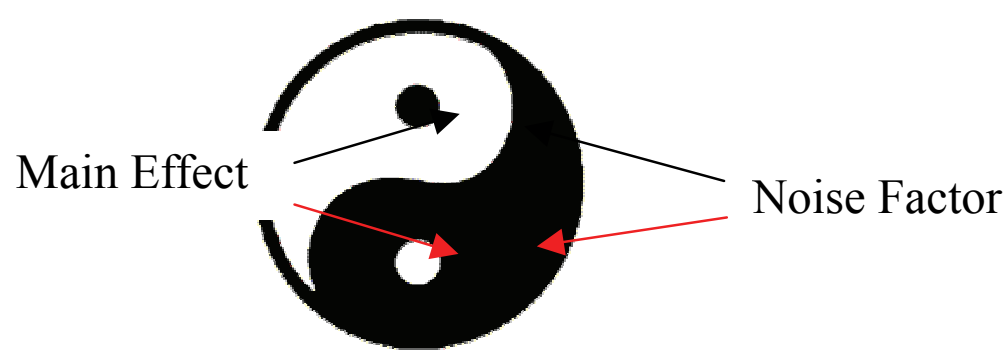

Figure 1. Main Effect Factor and Noise Factor 
Decision makers are constantly eager to reselect quality characteristics for accurately monitoring process quality without incurring additional costs. The question then arises of how to make appropriate decisions. Generally, based on cost, operability, productivity and benefit considerations, most decision makers ignore uncontrolled noise factors. However, identifying which control factor is the main effect factor and which are noise factors has always confused decision makers seeking to make appropriate decisions. Thus, this chapter applies the Chinese philosophy of yin and yang, to illustrate relative management issues, and provide decision makers with philosophical thoughts for balancing the simultaneous consideration of various factors.

\section{Case Implementation}

The case firm divides departments according to by class of clean room. Process one is growing crystals. Moreover, process two includes slicing, edge grinding, lapping, backside treatment and etching. Process three includes wafer polishing, cleaning, packing and inspection. This chapter focuses on slicing, and thus more participants come from the process two departments than from other departments. In relative control and management philosophy procedure, three stages and steps of process are suggested. Figure 2 illustrates implement procedure of relative control and management philosophy.

\subsection{Focus Groups Processes}

Six steps are proposed for the focus groups processes. Figure 2 of stage 1 illustrates the focus groups implementation procedure.

Step 1.1: Specify the research and define the purpose

Focus groups require a clear, specific statement of purpose to develop appropriate questions and obtain the useful information. Statements of purpose that are broad and general create difficulty in identifying potential participants, developing questions, and obtaining useful results.

Step 1.2: Determine focus group participants

Generally, focus group participants must meet two criteria: 
1. they must have the process experience required by the research goals, and

2. they must be able to communicate this experience to the group.

This study required all participants to have process management experience and process quality control experience. The practical need to provide adequate communication among participants, the moderator, and project consultants made this requirement crucial. Four focus groups of 15 persons were conducted to identify the factors that influenced silicon quality and the process capability.

\section{Focus group 1:}

administrative department, four managers participating that include the general manager, department one manager, department two manager and department three manager.

\section{Focus group 2:}

engineer group, four persons participating that include department two of the section chief and three engineers.

\section{Focus group 3:}

quality control department, with the manager and section chief participating.

\section{Focus group 4:}

consultant group, involving a process consultant, whose main responsibility was to solve process problems at the firm; and four project consultants participated, whose main responsibilities were to increase yield and process capability.

Step 1.3: Decide the moderator

The moderator can control the influences on the success of the focus group. Therefore, the main role of the moderator is to facilitate open, uninhibited dialogue. Thus, the moderator should play several roles that depend on sensitive balancing and an objective and detached perspective. Especially, a focus group moderator should deal tactfully with outspoken group members, maintain the focus of the discussions, and ensure that every participant gets the opportunity to contribute. 
Step 1.4: Conduct the focus group and determine the method of data collection

The participants and moderator sat around a circle table. The discussions were recorded on tape and an assistant moderator took notes. The participants were asked to speak one at a time to ensure that all comments could be clearly heard on the tape. According, focus groups create knowledge of stable processes, optimal settings and quality control, all of which influence quality and process capability factors related to slicing problems. Auxiliary data sources include ISO documents, computer records and observations of behavior designed to help focus groups to make precise decisions.

Step 1.5: Discuss the topic of the slicing problems in the focus group

Slicing is an increasingly complex process. Effectively monitoring the individual product process stability and quality is difficult. However, when the yield of high quality wafers is unstable, or when the wire saw machine drifts, the inspector must carefully control and monitor the machine. Slicing is a kind of sawing that cannot easily yield the knife drift required of a wire knife. The work-piece can be damaged in three ways.

(1) Frequency changes may adjust the precision of the slicing machine.

(2) Controlling whole process quality by sampling is difficult, since production is in small batches. The crystal grown using the raw wafer material, such as a silicon ingot can be sliced into 250 300 pieces. Standard sampling requires only one or two wafers to be sampled to monitor and control slicing. Such a small number of samples cannot provide sufficient information to determine process quality.

(3) Engineers set parameters and change the type of material, thus destabilizing the slicing. 


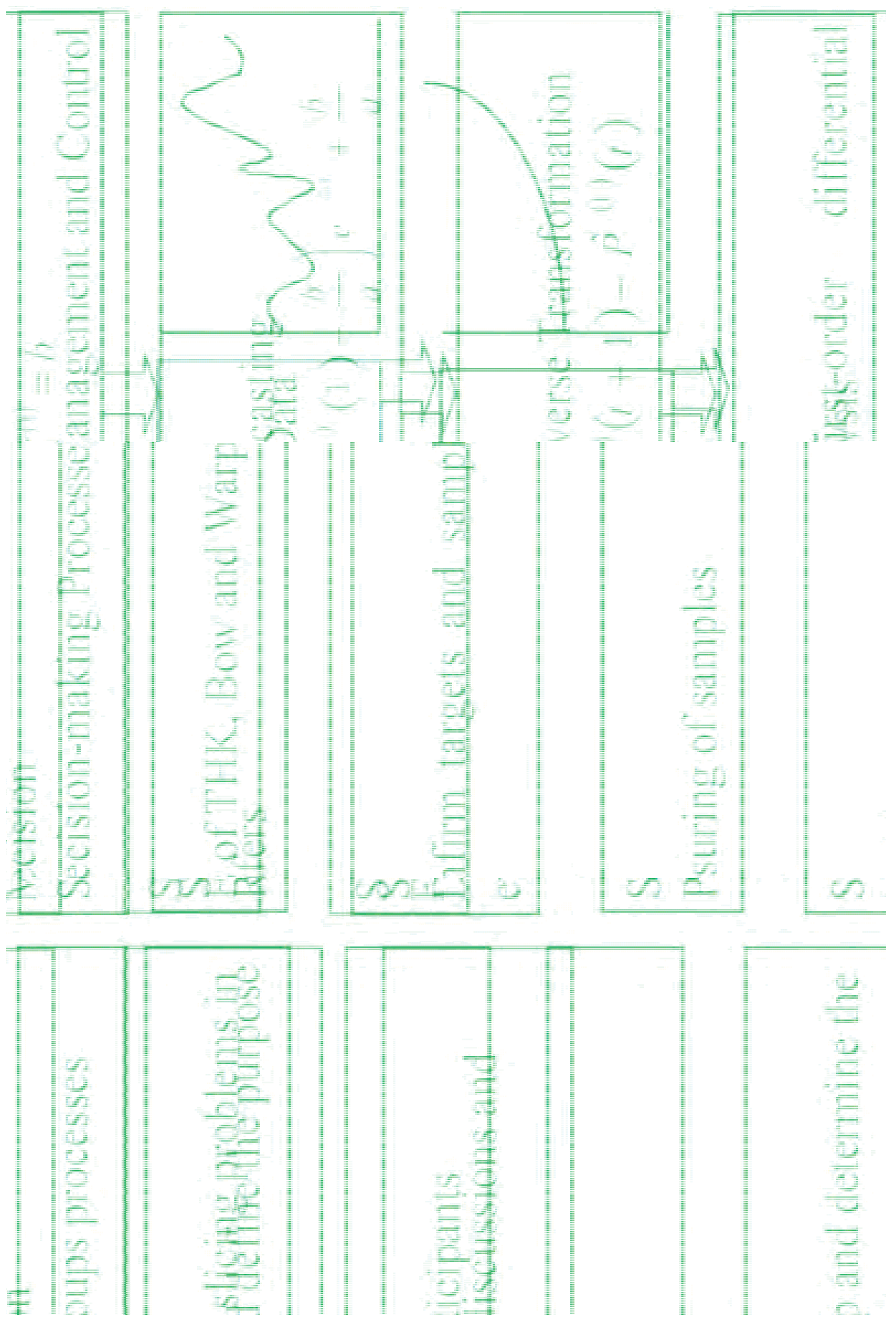

Figure 2. Relative Management and Control Implementation Procedure 
Two topics are identified based on the above, including wire knife drift, abnormal work-piece impact yield following slicing, and the influence of parameters on PCIs:

(1) Adjusting the wire knife drift influences sliced wafer quality

This topic relates to the adjusting wire knife time and engineering procedures. Managing knowledge concerning the slicing knife can increase yield, quality and process capability.

(2) Influence of parameters on process capability

This topic concerns slicing machine precision and wire knife drift. The focus groups explore how parameter settings influence slicing stability.

Step 1.6: Verify the focus group discussions and results

To understand slicing problems of wire knife, defective yield, and parameters settings, all focus groups discussed how inspecting an entire ingot can require examining 284 wafer slices.

Adjusting wire knife drift influences slicing quality

\section{(A) Analyzing Wire Knife}

THK parameter was set to $750 \pm 30(\mu)$ and the bow was $\square 15(\mu)$. Figures 3 and 4 illustrate the processing of 284 wafers, including THK and various bow values, and wire knife times. Figure 3 illustrates the thickness variation and the wire knife adjusted time, the average THK is $760.222(\mu)$, the yield is 0.87 and the wire knife is adjusted 44 times. The wife knife was adjusted once, and adjusted time appearance at the 14th, 18th and 29th sliced wafers, and so on. The wire knife was repeatedly adjusted, and adjust time appear at the sliced wafers of 72nd 75th, 126th 132nd, 141st 143rd and 223rd 228th. Figure 4 reveals that the average bow is $7.549(\mu)$, while the standard deviation is $12.78(\mu)$ and the yield is 0.83 . Figure 4 shows that when executing the procedure of adjusted wire knife, the bow becomes extremely unstable and this unstable variation influences the following wafers.

Statistical data from Figure 4 reveals that engineers identified the following problems with adjusting the wire knife: (1) Adjusting the wire knife is appropriate, but the engineers do not perform the adjustment procedure, with a probability of 0.43 ; or (2) it is not yet time to adjust the wire knife but engineers 
perform the adjustment procedure, with a probability of 0.20 . The postadjustment wafer yield is just 0.57 , and the inspected machine gradually increases the process capability. Consequently, engineers should separate individual wafers from the preceding and following ones when adjusting the wire knife. Such separation reduces the likelihood of problems occurring in subsequent edge grinding and lapping processes. The focus groups concluded that two general causes exist for unstable slicing. When the machine appears unstable, engineers can stabilize the slicing by adjusting the wire knife. Moreover, if the wire knife undergoes considerable abrasion and engineers have adjusted the wire knife, the slicing becomes extremely unstable.

(B) Concluding the Results

The focus groups concluded that unstable wire knife causes poor bowing, and adjusting the wire knife cannot reduce the defect rate to below that of bow. Therefore, firm should focus on controlling bow quality. Slicing problems can be classified as either machine or engineer-related. These problems can be further subdivided into another two groups, namely machine-related problems and human-related problems.

Machine-related problems arise after long periods of continuous saw operation, and involve reduced machine precision impacting quality and yield. The saw machine must be periodically adjusted. Meanwhile, human-related problems typically relate to the wire knife procedures used, which are crucial to stabilizing slicing.

The wire knife is adjusted based on engineer experience, and no specific rules are followed. Inexperienced engineers are likely to make the THK too thick or too thin, meaning the anticipated results will not be obtained.

Engineer adjustments to the wire knife involve adjusting the pressure, angle and force. Engineers can use a wafer box with a different color to the color box used online to distinguish abnormal wafers and thus facilitate inspection. Hence, firms must standardize their procedures. Timely application of engineer expertise is critical in the slicing process. Every engineer must be educated and be knowledgeable regarding methods of increasing yield.

(2) Parameters that influence process capability

(A) Process Capability Analyze

Cpk is conventionally used to assess process capability and process variation 


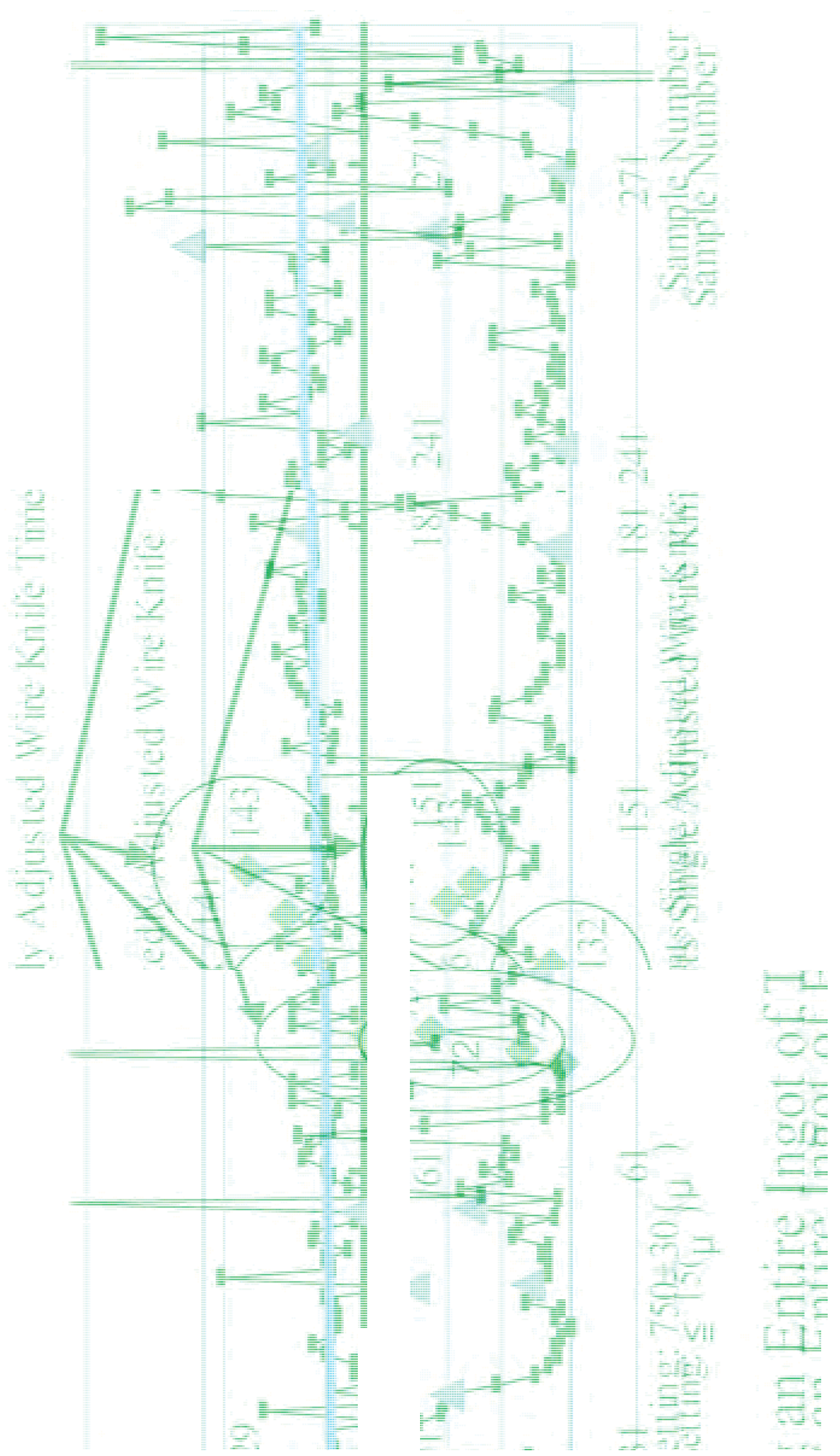

Figure 3. Inspecting an Entire Ingot of THK
Figure 4. Inspecting an Entire Ingot of Bow 
In the semiconductor industry, and is defined as,

$$
C_{p k}=\min \left\{C_{p u}(U), C_{p l}(L)\right\}
$$

where $C_{p u}(U)=\frac{U S L-\mu}{3 \sigma}, C_{p l}(L)=\frac{\mu-L S L}{3 \sigma}$; USL denotes the upper specification limit and LSL is the lower specification limit; $\mu$ represents the process mean, and $\sigma$ is the standard deviation under constant controlled conditions.

In the subject firm, the parameter settings include THK, bow, knife rotational speed and slicing speed. The Cpk value of THK and bow is set at 1.0. Table 1 lists the THK quality characteristic, using Eq. (8) to calculate the process capabilities $\mathrm{Cpu}, \mathrm{Cpl}$ and $\mathrm{Cpk}$. Column 2 illustrates the parameter of THK, $750 \pm 30(\mu) . \mathrm{Cpl}=1.128$ is significantly higher than $\mathrm{Cpu}=0.555$ and $\mathrm{Cpk}=0.555$, demonstrating that slicing process capability is unstable. However, the average THK for slicing is 760.222( $\mu$ ); that is the central line is increased by $10.222(\mu)$. Column 3 illustrates the parameter for THK assumption shifting $10(\mu)$ to $760(\mu)$, and the Cpk index is recalculated as 0.738. Notably, CpU and CpL are stable. The right column reveals the defective yield after adjusting the wire knife, and the Cpk index is recalculated as 1.084, consistent with the standard process capability, $\mathrm{Cpk}=1.0$. Consequently, the groups suggest that engineers check the THK parameter setting and the wire knife vibration. Following any adjustment of the wire knife, engineers should perform wafer slicing before proceeding to the next process. Table 2 presents the bow quality characteristic process capabilities, $\mathrm{Cpu}, \mathrm{Cpl}$ and $\mathrm{Cpk}$. The $\mathrm{Cpk}$ index for the slicing process capability is always unstable; the Cpk index for the slicing process capability is unstable. This finding relates to slicing quality yield and also influences edge grinding, lapping and polishing. The bow of PCI is lower than that of THK. The bow instability reduces lapping and polishing process yield.

(B) Reaching Conclusions

The focus groups concluded that the causes of machine instability can be classified into three problem types, all machine related:

(a) First, engineers can use the Taguchi method to modify parameter settings to raise process capability. 


\begin{tabular}{l|lll}
\hline Parameter Setting & $\begin{array}{lll}\text { Customer Target } \\
750(\mu)\end{array}$ & $\begin{array}{l}\text { Target Shift } 10 \mu \\
760(\mu)\end{array}$ & $\begin{array}{l}\text { Take of Defective } \\
\text { Wafer }\end{array}$ \\
\hline Upocess Capability & 0.555 & 0.756 & 1.122 \\
Lower PCI (CpL) & 1.128 & 0.738 & 1.084 \\
PCI (Cpk) & 0.555 & 0.738 & 1.084 \\
\hline
\end{tabular}

Table 1. PCIs Analysis THK Quality Characteristic

\begin{tabular}{l|lll}
\hline & Parameter Setting & $\begin{array}{l}\text { Customer Target } \\
15(\mu)\end{array}$ & $\begin{array}{l}\text { Take of Defective } \\
\text { Wafer }\end{array}$ \\
Process Capability & 0.539 & 0.606 & \\
\hline Upper PCI (CpU) & 0.544 & 0.589 & \\
Lower PCI (CpL) & 0.539 & 0.689 & \\
PCI (Cpk) &
\end{tabular}

Table 2. PCIs Analysis Bow Quality Characteristic

(b) Second, the defect ratio increases with wafer size. Therefore, 8 -inch wafers have a lower yield than 4-, 5-, and 6-inch wafers. Moreover, when slicing an 8inch ingot, engineers must inspect and tightly control the wire knife for the bow to reduce abnormalities.

(c) Third, the wire knife life cycle severely influences process capability. Generally, a wire knife can slice 1000-1200 wafers. However, wire knives break easily. To prevent knife breakage, engineers can use a model to forecast knife life cycle. Extremely unstable bow value indicates that it is time to replace the old wire knife with a new one.

(C) PCIs Verifying Analysis of 4-, 5-, 6-, and 8-inch Wafers

To verify the effectiveness of the new parameter settings, engineers monitor the slicing of 4-inch, 5-inch, 6-inch and 8-inch ingots. Table 3 lists the PCIs of the THK and bow quality characteristics. The 4-inch ingot has THK parameter setting of $525 \pm 15(\mu)$ and bow parameter setting of $\square 10(\mu)$. The ingot can be sliced into 346 pieces. The PCI of the THK quality characteristic is 2.60 and the bow quality characteristic is 1.84 . Table 3 confirms that the 5-inch, 6-inch and 
8-inch ingots PCIs of the bow are lower than those of THK. Notably, the process capability reduces when slicing large wafers, namely, 8-inch wafers have lower PCIs than 4-, 5-, and 6-inch wafers. Especially the bow PCI $=0.83$ for slicing an 8-inch ingot, which is below the customer value (PCIs $=1.0$ ). Consequently, 8-inch ingot slicing should be carefully monitored and the bow tightly controlled to reduce abnormalities.

\begin{tabular}{|c|c|c|c|c|c|c|c|c|}
\hline Wafer Size & 4-Inch & & 5-Inch & & 6-Inch & & 8-Inch & \\
\hline & THK & Bow & THK & Bow & THK & Bow & THK & Bow \\
\hline $\begin{array}{l}\text { Customer } \quad \text { Specification } \\
(\text { Unit: } \mu)\end{array}$ & $525 \pm 15$ & $\square 10$ & $625 \pm 30$ & $\square 100$ & $525 \pm 20$ & $\square 40$ & $853 \pm 30$ & $\square 100$ \\
\hline Sample Size & 346 & 346 & 334 & 334 & 181 & 181 & |334 & 334 \\
\hline Cpk & 2.60 & 1.84 & 1.64 & 1.46 & 1.40 & 1.01 & 1.07 & 0.83 \\
\hline
\end{tabular}

Table 3. PCIs Analysis THK and Bow Process Capability of 4-, 5-, 6-, and 8-inch Wafers

Consequently, decision makers must own enough wisdom to judge, supervise and evaluating trade-offs multiple decision problems. Typically, slicing problems can be divided into machine and engineer-related. A fishbone diagram derived from the preceding is illustrated in Figure 5. These problems can be further subdivided as follows.

(A) Four machine-related problem types.

(1) The saw operates for a long time, and machine precision impacts quality and yield. The saw machine must be periodically adjusted.

(2) Engineers can use quantity method, such as the parameter design of Ta guchi methods to modify parameters setting to increase process capabil ity.

(3) When producing large size of wafer, the risk of defective yield increases. Therefore, 12-inch wafers have a lower yield than 4-, 5-, 6- and 8-inch wa fers. Moreover, when slicing an 8-inch ingot, engineers must inspect and tightly control bow to reduce abnormalities. 
(4) The wire knife life cycle severely affects process capability. Generally, a knife can slice 1000-1200 wafers. The wire knife breaks easily. To prevent the knife's break, engineers can use a forecast model to predict the knife life cycle. If the bow value successive extremely unstable, then it is time to change a new wire knife.

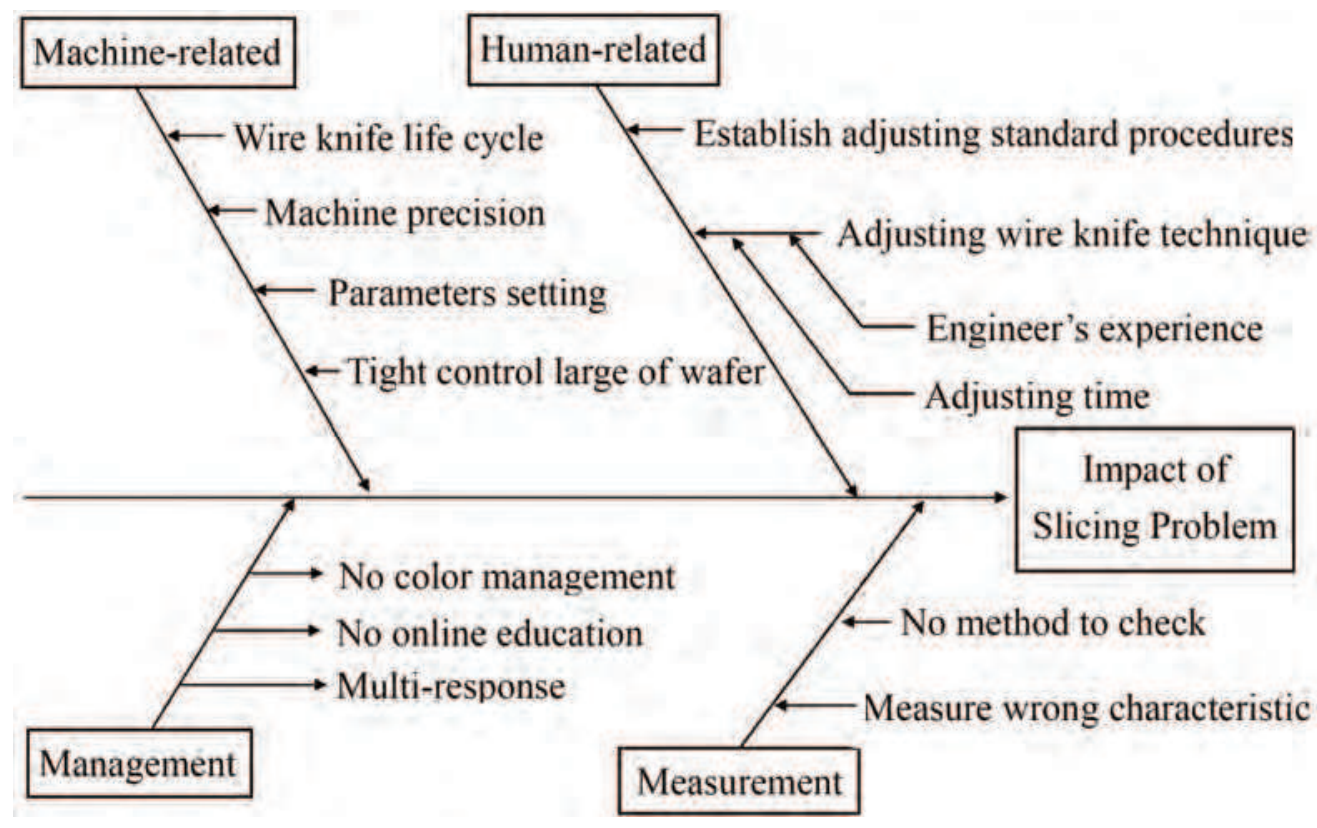

Figure 5. Slicing Problems of Root Causes

(B) Three human-related problem types.

(1) Usually, adjusting the wire knife procedures is the most important technique for stabilizing the slicing. The wire knife is adjusted according to an engineer's experience, and no rules are followed. If engineers have insufficient experiences, they are likely to make the THK too thick or too thin. The anticipated results will not be obtained. When an engineer adjusts the wire knife, he or she must adjust the pressure, angle and force. Engineers can use a different color wafer box from the online used color box to distinguish abnormal wafers for convenient inspection. Taguchi methods can solve problems of multi-response quality characteristics. 
(2) The setting up of the wire knife affects the slicing yield. Hence, the firm must establish standard procedures. Timely application of an engineer's expertise is critical in the slicing process.

(3) Every engineer must be educated and have relevant knowledge increase yield.

Above analysis allow engineers to clearly understand how quality and process capability affect silicon wafer slicing. Interactive discussions indicate that the decision-making groups can enhance the productivity and effectiveness of decision-making, either by accelerating the decision-making process or by increasing the quality of the resulting decisions. Moreover, the proposed procedure allows an engineer to adjust rapidly a manufacturing system to eliminate problematic phenomena and increase slicing quality and process capability.

\subsection{Grey Situation Decision-Making Processes}

Six steps are proposed for the GSDM processes. Figure 2 of stage 2 illustrates the GSDM implementation procedure.

Step 2.1: Randomly sample five wafers

Sample five work-pieces whose samples have been completely confirmed at random, and measure the multiple quality characteristics at five points on each work-piece, using an ADE6300, measuring instrument. Then average the measured data of these points (See Table 4.)

\begin{tabular}{l|lllll}
\hline \multirow{2}{*}{$\begin{array}{l}\text { Quality } \\
\text { Characteristics }\end{array}$} & \multicolumn{5}{|l}{ Work-pieces of Sample } \\
\cline { 2 - 6 } & 1 & 2 & 3 & 4 & 5 \\
\hline THK & 789.00 & 744.00 & 759.00 & 753.00 & 752.00 \\
Warp & 26.60 & 20.80 & 27.00 & 22.80 & 21.90 \\
Bow & 10.90 & 16.80 & 15.95 & 16.05 & 16.70 \\
\hline
\end{tabular}

Table 4. Measured Multiple Quality Characteristics of Wafer (Unit: $\mu)$

Step 2.2: Decide upon the situations, confirm the targets and sample events.

(1) Event: decide the screening samples of the quality characteristics, and can be defined as $a_{1}$. 
(2) Countermeasure quality characteristic 1 , THK (defined as $b_{1}$ ); quality characteristic 2, warp (defined as $b_{2}$ ); quality characteristics 3 , bow (defined as $b_{3}$ ).

(3) Situation:

$S_{11}=\left(a_{1}, b_{1}\right)$ (sample screening of the quality characteristics; countermeasure for quality characteristic 1 ). In $S_{i j}, \mathrm{i}$ is the index of the sample; $j$ is the index of the quality characteristics.

$S_{12}=\left(a_{1}, b_{2}\right)=\begin{aligned} & \text { (sample screening of the quality characteristics; countermea- } \\ & \text { sure for quality characteristic } 2)\end{aligned}$

$S_{13}=\left(a_{1}, b_{3}\right)=\begin{aligned} & \text { (sample screening of the quality characteristics; countermea- } \\ & \text { sure for characteristic } 3)\end{aligned}$

(4) Target:

Target 1: $\quad$ THK is the target-is-the-best effective measured value, and $E_{11}^{1}=789, E_{21}^{1}=744, E_{31}^{1}=759, E_{41}^{1}=753, E_{51}^{1}=752$.

Target 2: $\quad$ Warp is the lower-the-better effective measured value, and $E_{12}^{2}=26.6, E_{22}^{2}=20.8, E_{32}^{2}=27.0, E_{42}^{2}=22.8, E_{52}^{2}=21.9$.

Target 3: $\quad$ Bow is the lower-the-better effective measured value, and $E_{13}^{3}=10.9, E_{23}^{3}=16.8, E_{33}^{3}=15.95, E_{43}^{3}=16.05, E_{53}^{3}=16.7$.

Step 2.3: Measuring the samples

According Step 2.2, THK, warp and bow are the target-is-the-best, lower-thebetter, and lower-the-better quality characteristics, respectively. The dimensionless linear normalization is simplified as,

Target 1: Use Eq. (4) to compute the effective measured value of THK,

$$
E_{0}^{1}=\frac{1}{5}(789+744+\ldots+752)=759.4
$$

and 
$R_{11}^{1}=\frac{\min \left\{E_{11}^{1}, 759.4\right\}}{\max \left\{E_{11}^{1}, 759.4\right\}}=\frac{759.4}{789}=0.9625$

Similarly, $R_{21}^{1}=0.9797, \quad R_{31}^{1}=0.9995, \quad R_{41}^{1}=0.9916$ and $R_{51}^{1}=0.9903$.

Target 2: $\quad$ Use Eq. (3) to compute the effective measured value of warp,

$$
R_{12}^{2}=\frac{\min _{i} E_{i j}^{2}}{E_{12}^{2}}=\frac{20.8}{26.6}=0.7820
$$

Similarly,

$$
R_{22}^{2}=1, R_{32}^{2}=0.7704, R_{42}^{2}=0.9123
$$

and

$$
R_{52}^{2}=0.9498 \text {. }
$$

Target 3: Use Eq. (3) to compute the effective measured value of bow,

$$
\begin{aligned}
& R_{13}^{3}=\frac{\min _{i} E_{i j}^{3}}{E_{13}^{3}}=\frac{10.9}{10.9}=1 \\
& R_{23}^{3}=0.6488, R_{33}^{3}=0.6834, R_{43}^{3}=0.6791 \text { and } R_{53}^{3}=0.6527 .
\end{aligned}
$$

Step 2.4: Make the grey situation decision

Eq. (5) yields the synthetic effective measured value as:

$$
\begin{aligned}
& R_{11}^{\Sigma}=\frac{1}{5}\left(R_{11}^{1}+R_{21}^{1}+\ldots+R_{51}^{1}\right)=\frac{1}{5}(0.9625+0.9797+\ldots+0.9903)=0.9847 \\
& \text { Similarly, } R_{12}^{\Sigma}=0.883 \text { and } R_{13}^{\Sigma}=0.7328
\end{aligned}
$$

Thus, the worst quality characteristic in the wafer is bow. Bow is therefore monitored. However, the firm currently monitors the THK quality characteristic. The synthesized effective measured values of THK are the highest. Therefore, the process capability of THK is very stable and the manufacturer need not spend much money or time to inspect and monitor this characteristic. 
Step 2.5: EWMA (Robert, 1959; Lucas and Saccussi, 1992) verifying analysis of THK and bow

Based on the adjusting the drift of the wire knife impacts the quality of slicing discussions, the exponential weighted moving average (EWMA) control chart is presented to demonstrate and verify the feasibility and effectiveness of proposed discussions.

In this step, an EWMA control chart detects and quickly sets off the alarm in the case of an abnormality quality quickly. Therefore, the method can effectively monitor a little drift in the process. The effective measured value of bow and THK are plotted on an EWMA chart. A univariate EWMA chart is modeled as

$$
Z_{t}=\lambda \bar{X}_{t}+(1-\lambda) Z_{t-1}, \quad t=1,2, \ldots, n
$$

Where $\lambda$ is the weighting factor (defined by the decision maker) and typical values for $\lambda$ are between 0.05 and 0.3 in SPC applications; $\bar{X}_{t}$ is the subgroup average for the current subgroup at time $t$ (or the current observation if the subgroup size is one $(n=1)$; the value of $Z$ at time zero, $Z 0$, is either a target value or the overall average of the selected subgroups (also defined by the decision maker).

The upper and lower control limits for the EWMA statistics are as follows.

$$
U C L=Z_{0}+\frac{3 \sigma}{\sqrt{n}} \sqrt{\left(\frac{\lambda}{1-\lambda}\right)\left(1-(1-\lambda)^{2 i}\right)}
$$

and

$$
L C L=Z_{0}-\frac{3 \sigma}{\sqrt{n}} \sqrt{\left(\frac{\lambda}{1-\lambda}\right)\left(1-(1-\lambda)^{2 i}\right)}
$$

where $\mathrm{Z} 0$ is the starting value (defined by the decision maker as either the target value or the process mean value), and $n$ is the size of the subgroup.

The process standard deviation, $\sigma$, is estimated using the $\bar{X}$ chart and setting $\lambda=0.3$ and $n=2$ to monitor and inspect bow and THK. In this chart, 124 samples are generated while the process is controlled. 
The measured data for bow are obtained from the machine sensors, and the THK is inspected at five points on each work-piece by the measuring instrument, ADE6300 and averaging these points as a point in Figure 6.

In Figure 6, two machine sensors, S1 and S2, monitor the slicing process. S1 is near the slicing plane of the work-piece and monitors bow characteristic. For example, in Figure 7, the bow value is the mean of the max and min values of the drifts, $(2+7) / 2=4.5$. S2 is near the slicing knife and monitors the vibration of the knife. In this paper, S1 is only used for the bow, but S2, which helps to prevent $\mathrm{S} 1$ from measuring in a biased way, is not directly related to the Bow.

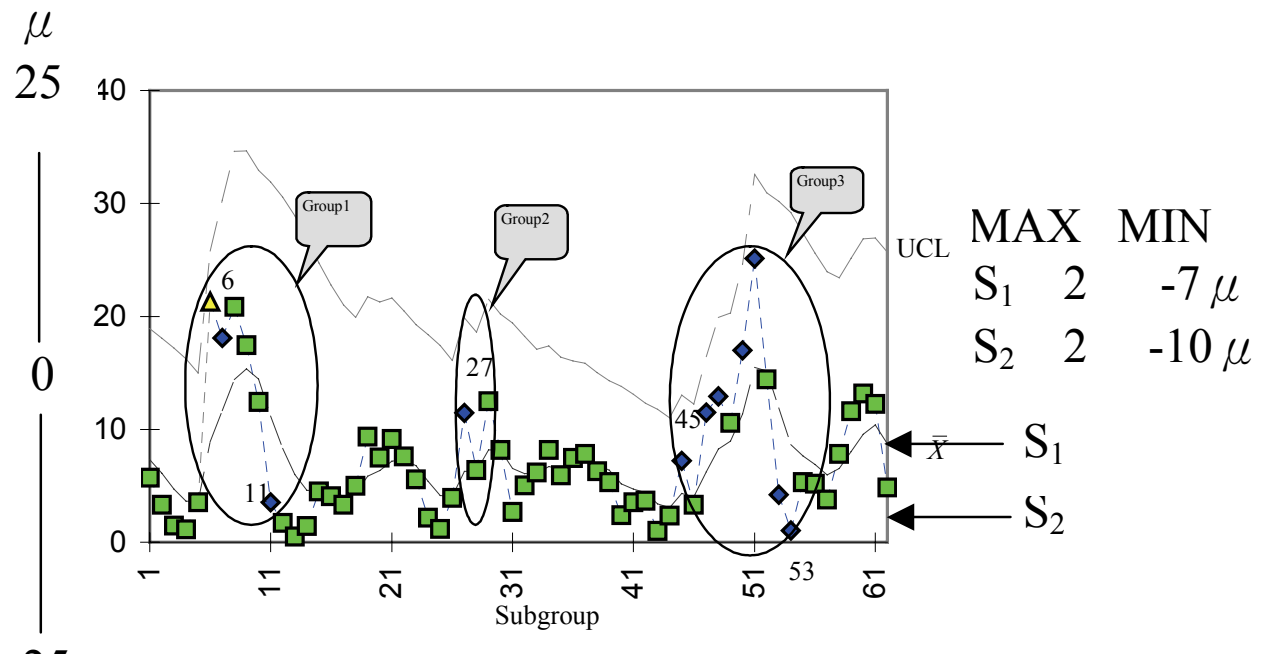

Figure 6. The Machine Sensors of Bow Information

Figure 7 shows an upper bound of the bow's EWMA chart by $\bar{X}$ counts and Figure 8 shows the THK. In Figure 7, the out-of-control conditions appear at the 6th, 27th and 45th signals. In Figure 8, the process is out-of-control at the 26th and 46th signals. The abnormal quality alarms of bow in Groups 2 and 3 are the same as those of THK in Groups 1 and 2. In Figure 7, the out-of-control signals start from the 6th $\bar{X}$ count, but in Figure 8 the $\bar{X}$ count of THK is under control.

Consequently, the quality of bow should be monitored more frequently than the quality of THK. Therefore, the effectiveness of monitoring the worst char- 
acteristic, bow, using an EWMA control chart is the same as that of using the GSDM; that is, bow dominates other characteristics.

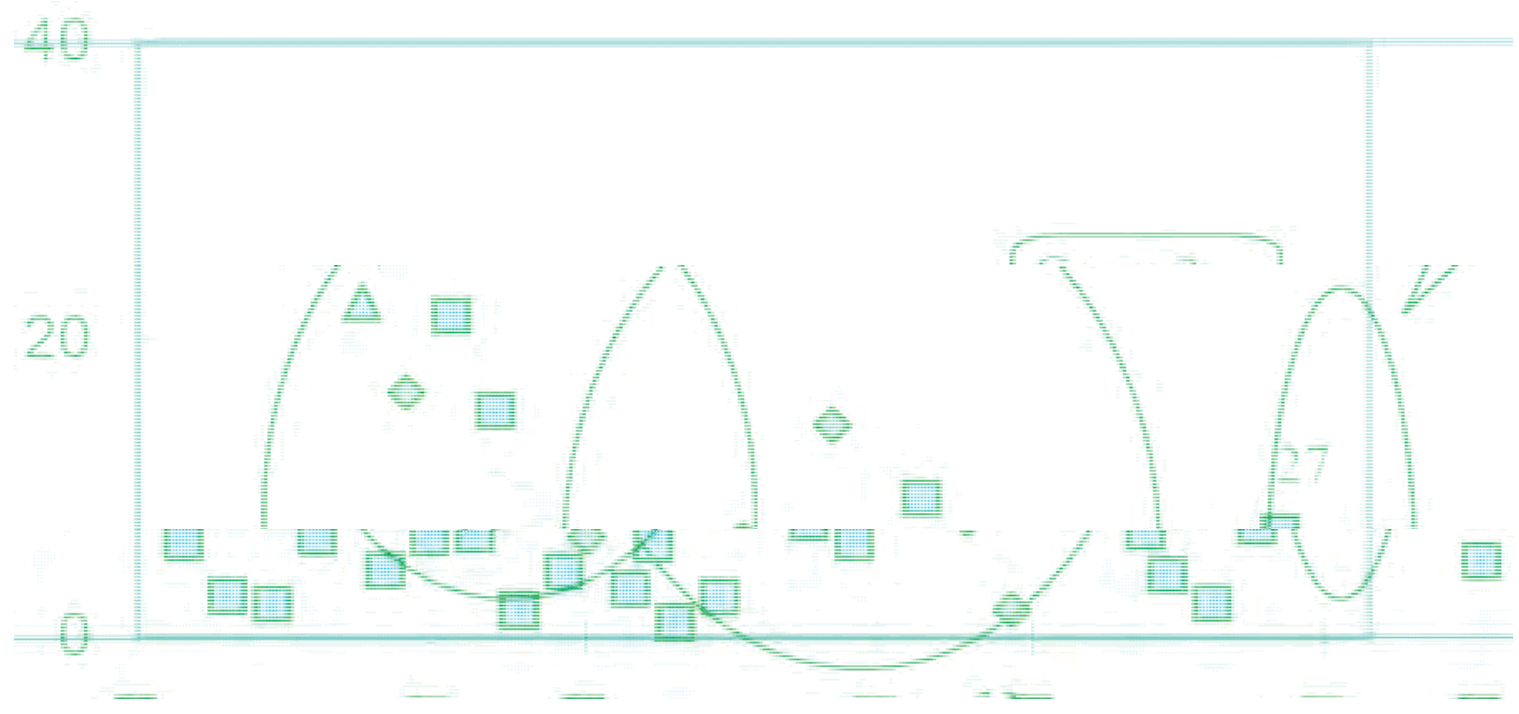

Figure 7. Upper Side of Bow's EWMA Chart by $\bar{X}$ Counts

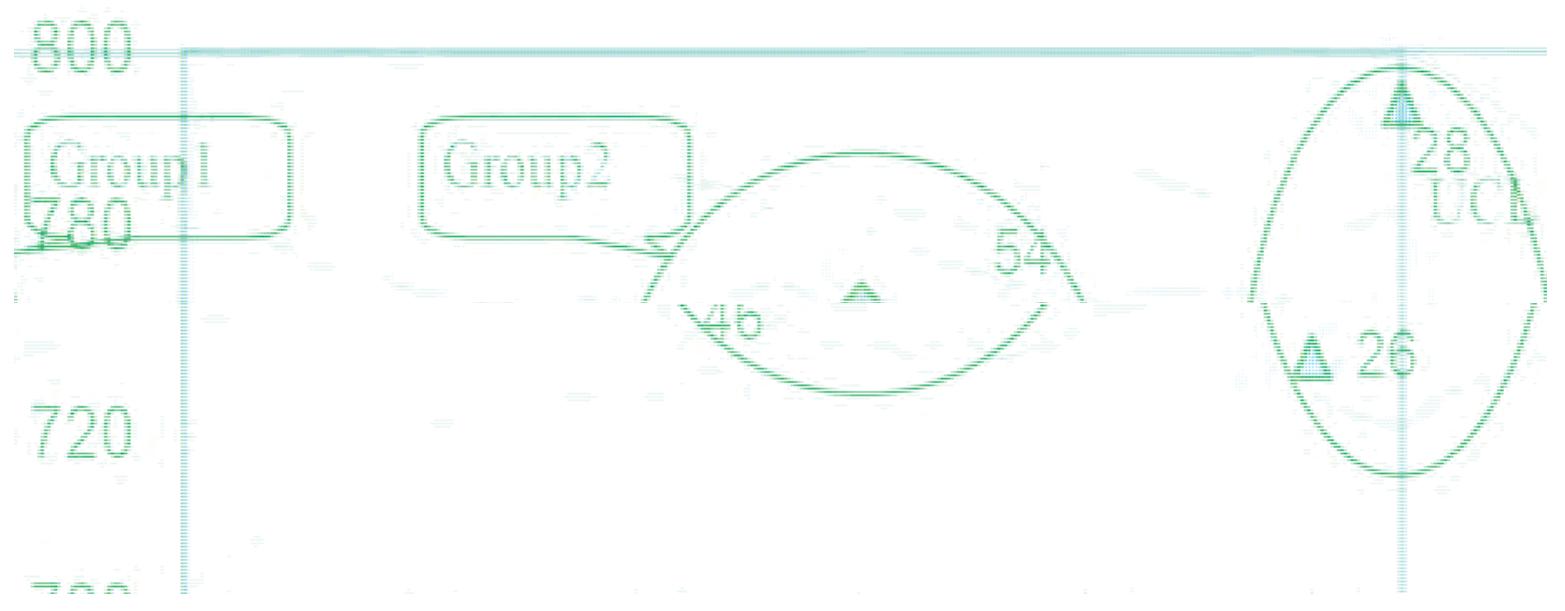

Figure 8. THK's EWMA Chart by $\bar{X}$ Counts

Step 2.6: Final decision-making

(1) By the GSDM, or the EWMA control chart, bow is the worst quality characteristic. Bow is thus unstable in the slicing process. 
(2) According to the definition of THK (ASTM F534, 1995; ASTM F657, 1995), the distance between $a$ and $b$ can be altered by subsequent lapping and polishing. However, bow and warp, cannot be changed. Hence, bow is the critical characteristic, but THK influences the quality of the wafer.

\subsection{Relative Management and Control}

Simultaneously monitoring and controlling multiple quality characteristics is costly. Above the result of GSDM processes, bow is the most difficult quality characteristic to monitor and control. Bow characteristic can be considered the main effect factor, and the other characteristics, such as THK and warp characteristics can be considered noise factors. Decision makers can apply the slicing machine sensors to costlessly balance the main effect factor and the noise factors. By using the concept of yin and yang variation and collocating grey forecasting, GM (1, 1) model (Deng, 1989 and 2003; Lin and Lin, 2001; Hsieh, et al., 2002; Lin and Yang, 2003), precise drift and quality control from the slicing machine can be constantly monitored and forecast. If the GM $(1,1)$ model can accurately predict Bow value, then the main effect factor, noise factors and parameter settings are balanced and the slicing process is controlled. Otherwise, the slicing process and parameter settings were not controlled.

Table 5 lists and compares four forecasting models, namely the GM $(1,1)$ model, regression model, time series and neural network. Deng $(1989,2003)$ demonstrated that four-data is used to construct the GM $(1,1)$ model and forecast. In the slicing process, a small batch size production model cannot provide sufficient information to clarify the quality of the entire process. That is, available data are insufficient for designing a predictive model, but Grey forecasting does not require much data. In conventional forecasting methods, decision makers deal with variables by considering numerous samples, and then analyze and compare the relationships among these samples by assuming that populations must obey some identified distribution. However, Grey forecasting can be used with very few data and can use an arbitrary distribution of data to forecast output value. The main feature of "Grey forecasting" is that it can be used with limited data, including just three or four observations, and can make an objective forecast based on an arbitrary data distribution (Deng, $1989,2003)$. The Grey forecasting model thus is extremely appropriate for forecasting and controlling the slicing process of the small batch size production model. 
The Grey system theory treats all variables as a grey quantity within a certain range. Grey forecasting model then accumulates available data to derive the internal regularity. The model examines the nature of internal regularity in managing the disorganized primitive data. The model was established by transferring the arranged sequence into a differential equation.

\begin{tabular}{|c|c|c|c|c|}
\hline & \multicolumn{4}{|c|}{ Methodology } \\
\hline & $\operatorname{GM}(1,1)$ & Regression Model & Time Series & Neural Network \\
\hline Data & $\geqq 4$ & $\begin{array}{c}\geqq 30 \\
\text { (suggested) }\end{array}$ & $\begin{array}{l}\geqq 100 \\
\text { (suggested and as } \\
\text { much as better) }\end{array}$ & as much as better \\
\hline Model Complexity & Low & Low & High & Low \\
\hline Self Learning Ability & Yes & No & No & Yes \\
\hline Model Style & Dynamic & Statistic & Statistic & Dynamic \\
\hline
\end{tabular}

Table 5. Compare Forecasting Methodologies

The following illustration thoroughly describes the method used to construct the model adopted herein by creating a sequence of one order linear moving GM $(1,1)$. Figure 2 of stage 3 presents the first order differential equation of GM $(1,1)$ model and the algorithms of the method are as follows (Deng, 2003; Lin and Yang, 2003; Lin et al., 2005):

Step 3.1: Establish original data series

$$
X^{(0)}=\left(P^{(0)}(1), P^{(0)}(2), \cdots, P^{(0)}(n)\right)
$$

The variables, including $P(1), P(2), \cdots$, and $P(n)$, are used to construct the Grey forecasting model.

Step 3.2: Build accumulated generating operation (AGO) series

When a model is constructed, the Grey system must apply one order accumulated generating operation (AGO) to the primitive sequence in order to provide the middle message of building a model and to weaken the variation ten- 
dency. In the slicing process, the production system can be regarded as a closed system. The main effect factor and noise factors simultaneously exist in a wafer during slicing. According to AGO, noise factors can thus be eliminated (Deng, 1999). Herein, $X^{(1)}$ is defined as $X^{(0)}$ 's one order AGO sequence. That is,

$$
\begin{aligned}
X^{(1)} & =\left(P^{(1)}(1), P^{(1)}(2), \cdots, P^{(1)}(n)\right) \\
& =\left(\sum_{t=1}^{1} P^{(0)}(t), \sum_{t=1}^{2} P^{(0)}(t), \cdots, \sum_{t=1}^{n} P^{(0)}(t)\right)
\end{aligned}
$$

Step 3.3: Establish the first-order differential equation

$$
\frac{d X^{(1)}}{d t}+a X^{(1)}=b
$$

Where $t$ denotes the independent variables in the system, $a$ represents the developed coefficient, $b$ is the Grey controlled variable, and $a$ and $b$ denote the parameters requiring determination in the model.

Step 3.4: Compute AGO forecasting

The approximate relationship can be obtained as follows by substituting $\hat{a}$ obtained in the differential equation, and solving Eq. (14):

$$
\hat{P}^{(1)}(t+1)=\left(P^{(0)}(1)-\frac{b}{a}\right) e^{-a t}+\frac{b}{a}
$$

where

$$
\widehat{a}=\left[\begin{array}{l}
a \\
b
\end{array}\right]=\left(B^{T} B\right)^{-1} B^{T} Y_{N}
$$




$$
\begin{aligned}
& B=\left[\begin{array}{cc}
-\frac{1}{2}\left[P^{(1)}(1)+P^{(1)}(2)\right] & 1 \\
-\frac{1}{2}\left[P^{(1)}(2)+P^{(1)}(3)\right] & 1 \\
\vdots & \vdots \\
-\frac{1}{2}\left[P^{(1)}(n-1)+P^{(1)}(n)\right] & 1
\end{array}\right] \\
& Y_{N}=\left[P^{(0)}(2), P^{(0)}(3), \cdots, P^{(0)}(n)\right]^{T}
\end{aligned}
$$

\section{Step 3.5: Compute AGO's inverse transformation}

When $\hat{P}^{(1)}(1)=\hat{P}^{(0)}(1)$, the acquired sequence one order Inverse-Accumulated Generating Operation (IAGO) is acquired and the sequence that must be reduced as Eq. (16) can be obtained.

$$
\hat{P}^{(0)}(t+1)=\hat{P}^{(1)}(t+1)-\hat{P}^{(1)}(t)
$$

where $\hat{P}^{(1)}(t+1)$ is the predicted value of $\hat{P}^{(1)}(t+1)$ at time $k+1$.

Given $t=1,2, \cdots, n$, the sequence of reduction is obtained as follows:

$\hat{X}^{(0)}=\left(\hat{P}^{(0)}(1), \hat{P}^{(0)}(2), \cdots, \hat{P}^{(0)}(n+1)\right)$

Where $\hat{P}^{(0)}(n+1)$ is the Grey elementary predicting value of $P(n+1)$.

\section{Step 3.6: Compute residual error}

After the above model is generated and developed, further tests are necessary to understand the error of forecasted value and actual value. To demonstrate the efficiency of the proposed forecasting model, this paper adopts the residual error test method to compare the actual value and forecasted value. Herein, Eq. (17) and Eq. (18) are used to compute the residual error and the average re- 
sidual error of Grey forecasting.

$$
\begin{gathered}
\text { Error }=\left|\frac{P(t)-\hat{P}(t)}{P(t)}\right| \quad j=1,2, \cdots, n . \\
\text { Average Error }=\frac{1}{n} \sum_{t=1}^{n}\left|\frac{P(t)-\widehat{P}(t)}{P(t)}\right| \quad j=1,2, \cdots, n .
\end{gathered}
$$

Currently, the firm applies the bow quality characteristic to monitor slicing quality, and thus this view can be accurately verified. The Bow parameter is set to $0 \pm 15(\mu)$ (customer object value), and the GM $(1,1)$ model is applied to forecast the Bow variation and wire knife. Compared with the online and forecasting values, if the forecasting values consistently exceed twice the $10 \%$ residual error, then an alarm in the slicing process system will sound. The alarm information indicates that the slicing system is unbalanced, and slicing quality may be out-of-control at the next wafer to be sliced. Therefore, engineers must adjust the wire knife and check the slicing process parameter settings. According to GM $(1,1)$ Grey forecasting model, this study estimates 40 samples as online verifying analysis and Table 6 lists the actual output values, forecasted output values and residual error.

The verifying and forecasting model comprises three parts. The first part is monitoring and forecasting slicing wafer from No. 1 to 8 . When the forecasting values exceed the $10 \%$ residual error by two times, the engineer does not stop the slicing machine to check and adjust the parameter settings of the correlative slicing process until the bow is out-of-control. The second part is monitoring and forecasting from No. 9 to 33 . When the forecasting values exceed twice the $10 \%$ residual error, the engineer stops the slicing machine to check and adjust the correlative slicing process parameters setting. The third part is monitored and forecast slicing wafer from No. 34 to 40. This part does not consider forecasting values until the bow is out-of-control.

This chapter uses part one samples to illustrate GM $(1,1)$ algorithms and the results are listed in columns 3 to 5 of Table 6 . The explanation follows:

From Eq. (12) and Table 6, the primitive sequence $X^{(0)}$ is 


$$
X^{(0)}=(14,7,9,9)
$$

\begin{tabular}{|c|c|c|c|c|c|c|c|c|c|}
\hline $\begin{array}{l}\text { No } \\
\text {. }\end{array}$ & $\begin{array}{l}\text { Actual } \\
\text { output } \\
\text { value }\end{array}$ & $\begin{array}{l}\text { Forecasted } \\
\text { output } \\
\text { value }\end{array}$ & $\begin{array}{l}\text { Residual } \\
\text { error (\%) }\end{array}$ & $\begin{array}{l}\text { Average } \\
\text { residual } \\
\text { error (\%) }\end{array}$ & No & $\begin{array}{l}\text { Actual } \\
\text { output } \\
\text { value }\end{array}$ & $\begin{array}{l}\text { Fore- } \\
\text { casted } \\
\text { output } \\
\text { value }\end{array}$ & $\begin{array}{l}\text { Residual er- } \\
\text { ror }(\%)\end{array}$ & $\begin{array}{l}\text { Average re- } \\
\text { sidual error } \\
(\%)\end{array}$ \\
\hline 1 & 14 & 14.000 & - & \multirow{5}{*}{0.055} & 21 & 13 & 13.387 & 0.030 & \multirow{13}{*}{0.041} \\
\hline 2 & 7 & 7.387 & 0.055 & & 22 & 11 & 10.592 & 0.037 & \\
\hline 3 & 9 & 8.290 & 0.079 & & 23 & 5 & 5.374 & 0.075 & \\
\hline 4 & 9 & 9.302 & 0.034 & & 24 & 3 & 2.726 & 0.091 & \\
\hline 5 & 11 & 10.438 & 0.051 & & 25 & 9 & 9.160 & 0.018 & \\
\hline 6 & 10 & 11.712 & 0.171 & & 26 & 9 & 8.656 & 0.038 & \\
\hline 7 & 10 & 13.142 & 0.314 & & 27 & 8 & 8.180 & 0.022 & \\
\hline 8 & 29 & - & - & & 28 & 8 & 7.730 & 0.034 & \\
\hline 9 & 7 & 7.000 & - & \multirow{4}{*}{0.026} & 29 & 7 & 7.304 & 0.043 & \\
\hline 10 & 8 & 7.826 & 0.022 & & 30 & 7 & 6.903 & 0.014 & \\
\hline 11 & 8 & 8.320 & 0.040 & & 31 & 9 & 8.845 & 0.017 & \\
\hline 12 & 9 & 8.845 & 0.017 & & 32 & 8 & 8.320 & 0.040 & \\
\hline 13 & 6 & 9.403 & 0.567 & & 33 & 8 & 7.826 & 0.022 & \\
\hline 14 & 5 & 9.996 & 0.100 & & 34 & 6 & 7.362 & 0.227 & \\
\hline 15 & 14 & 10.627 & 0.241 & & 35 & 6 & 6.925 & 0.154 & \\
\hline 16 & 10 & 10.000 & - & & 36 & 15 & 6.516 & 0.566 & \\
\hline 17 & 6 & 6.239 & 0.040 & & 37 & 14 & - & - & - \\
\hline 18 & 8 & 7.551 & 0.079 & & 38 & 14 & - & - & - \\
\hline 19 & 9 & 9.139 & 0.015 & & 39 & 18 & - & - & - \\
\hline 20 & 12 & 11.061 & 0.078 & & 40 & 27 & - & - & - \\
\hline
\end{tabular}

Table 6. Verifying Analysis

From Eq. (13), the one order AGO sequence of $X^{(1)}$ is obtained as follows:

$$
X^{(1)}=(14,21,30,39)
$$

Additionally, matrix $B$ and constant vector $Y_{N}$ are accumulated as follows: 


$$
B=\left[\begin{array}{ll}
-17.5 & 1 \\
-25.5 & 1 \\
-34.5 & 1
\end{array}\right] \quad Y_{N}=\left[\begin{array}{l}
7 \\
9 \\
9
\end{array}\right]
$$

From Eq. (14), $\hat{a}$ is obtained as

$$
\hat{a}=\left[\begin{array}{l}
a \\
b
\end{array}\right]=\left[\begin{array}{c}
-0.115 \\
5.357
\end{array}\right]
$$

This forecasting model is identified by incorporating $a$ and $b$ into Eq. (15)

$$
\hat{P}^{(1)}(t+1)=\left(P^{(0)}(1)+46.5\right) e^{(0.115) t}-46.5
$$

The forecast values 7.387, 8.290, 9.302, 10.438, 11.712 and 13.142 of the output value of slicing wafers from Nos. 2 to 7, respectively, are obtained by substituting $t=1,2, \cdots, 7$ into Eqs. (16) and (19), and the reduction sequence is

$$
\hat{X}^{(0)}=(7.387,8.290,9.302,10.438,11.712,13.142)
$$

From Table 6, which lists the actual output value of slicing wafer, the forecast output value of slicing wafer, residual error, and average residual error can be determined by substituting $\hat{P}^{(0)}(t+1)$ and $P^{(0)}(t+1), t=1,2, \cdots, 7$ into Eq. (17) and Eq. (18).

The first part of Table 6 involves two sections. The first section involves slicing wafer values from No. 1 to No. 5, while the second section involves slicing from No. 6 to No. 7. In the first section, the average residual error is 5.5\%. This section illustrates that the bow characteristic forecast output value could accurately forecast the actual output value. That is, the slicing process presents the normal situation and the parameter settings are balanced. However, in the second section, the residual errors are $17.1 \%$ and $31.4 \%$, respectively. Despite this, the two values are still under control and the engineer does not stop the slicing 
machine to check the parameter settings for the correlative slicing process. Thus, in the eighth slicing wafer value is out-of-control. Therefore, the unbalance forecasted values provide warning information that slicing process is unbalance. The second part involves three sections. The first section is slicing wafer values from No. 9 to No. 12; the second section involves slicing wafers from No. 13 to No. 15, and the third section involves slicing wafers from 16 to No. 33. In the first section, the average residual error is $2.6 \%$, indicating that the slicing process is under control. Although, the actual output values and the forecasted output values are under control in the second section, the residual errors are $56.7 \%, 10 \%$ and $24.1 \%$, and thus continue to exceed $10 \%$. The engineer stops the slicing machine and checks the correlative slicing process parameters setting. After checking the process parameter setting, the slicing process produces wafers effectively until No.33. In the third part, the residual errors from Nos. 34 to 36 are 22.7\%, 15.4\% and 56.6\%, respectively. These residual errors continue to exceed $10 \%$, but the actual output values are under control. The engineer does not consider forecasting values until the bow becomes out-of-control. The slicing process is unstable from No. 34 to 40. The noise factors from No. 34 to 36 are unbalanced and cause unstable yields.

\section{Conclusion}

Relative control and management philosophy includes three stages; they are focus groups, GSDM and relative management and control.

The first stage, focus groups processes allow engineers to clearly understand how quality and process capability influence silicon wafer slicing. Interactive discussions indicate that the focus groups can improve the productivity and effectiveness of decisions, either by accelerating the decision process or by increasing decision quality. Moreover, the proposed procedure allows engineers to rapidly adjust a manufacturing system to eliminate problematic phenomena and increase slicing quality and process capability.

The second stage, GSDM provides relative concept to screen the synchronously occurring abnormalities multiple quality characteristics. The main contribution of this paper is that is uses only five historical samples to screen out the worst quality characteristic from existing quality characteristics in the slicing process.

The third stage, relative management and control applies the Chinese philoso- 
phy of yin and yang to illustrate relative management of main effect factor and noise factor to control and monitor slicing process quality, and provides decision makers with philosophical thoughts for balancing the simultaneous consideration of various factors. Yin and yang refers to the Chinese idea of balance combined with continual change, an idea that can provide a continuous method of measuring and balancing slicing process. Furthermore, Grey forecasting detects and rapidly triggers the alarm in the case of an abnormality quality. Thus, the matching grey forecasting method is applied to increase process yield and accuracy of forecasting the quality of slicing the next wafer and constantly monitor accurate drift and quality control from the slicing machine.

Continuing to control and monitor slicing quality is not absolute, but rather requires balancing the two forces of "under control" or "out-of-control". Specifically, decision makers continue to monitor the slicing balance between the main effect factor and noise factors. Yin and yang thus is not a theory, thought or method. Instead yin and yang is a practical management philosophy that allows decision makers to use their hearts and minds to manage in a balanced way. Furthermore, it is essential for decision makers to learn the managerial art and wisdom of yin and yang philosophy.

\section{Acknowledgement}

The author would like to thank the author's master Dr. Hong Tao-Tze teaches the principle of yin and yang philosophy (www.taijimen.org) and the National Science Council of the Republic of China for financially supporting this research under Contract No. NSC 94-2416-H-264-007.

\section{References}

ASTM F534. (1995). Annual Book of ASTM Standards, ISBN: 0803122268.

ASTM F657. (1995). Annual Book of ASTM Standards, ISBN: 0803122268.

Deng, J. (1989). Introduction to Grey System Theory, The Journal of Grey System, 
Vol., 1 No., 1, pp.1-24, ISSN: 0957-3720.

Deng, J. (2003). Grey System Theory and Applications, Kao-Li, Taiwan, ISBN: 9575-847288.

Einstein, A. (1920). Relativity: The Special and General Theory, New York: Henry Holt and Company, ISBN: 1-58734-092-5.

Hsieh, C. H.; Chou, J. H. \& Wu, Y. J. (2002). Optimal Predicted Fuzzy PI Gain Scheduling Controller of Constant Turning Force Systems with Fixed Metal Removal Rate, The International Journal of Advanced Manufacturing Technology, Vol., 19, No., 10, pp. 714-721, ISSN: 0268-3768 (Paper) ISSN: 1433-3015 (Online).

Krueger, R. A. \& Casey, M. A. (2000). Focus Groups: A Practical Guide for Applied Research, 3rd Spiral edition, Sage Publications, Thousand Oaks, CA, ISBN: 0761920714.

Laozi \& Roberts, M. (Translator) (2004). Dao De Jing: The Book of the Way, University of California Press, ISBN: 0520242211.

Lin, C. T. \& Yang, S. Y. (2003). Forecast of the Output Value of Taiwan's Optoelectronics Industry Using the Grey Forecasting Model, Technological Forecasting \& Social Change, Vol., 70, No., 2, pp. 177-186, ISSN: 0040-1625.

Lin, C. T.; Chang, C. W. \& Chen, C. B. (2004). Focus Groups: Impact of Quality and Process Capability Factors on Silicon Wafer Slicing Process, International Journal of Manufacturing Technology and Management, Vol., 2, No., 2, pp. 171-184, ISSN: 1368-2148 (Print) ISSN: 1741-5195 (Online).

Lin, C. T.; Chang, C. W. \& Chen, C. B. (2005). Relative Control PhilosophyBalance and Continual Change for Forecasting Abnormal Quality Characteristics in a Silicon Wafer Slicing Process, The International Journal of Advanced Manufacturing Technology, Vol., 26, No., 9-10, pp. 1109 - 1114, ISSN: 0268-3768 (Paper) 1433-3015 (Online).

Lin, C. T.; Chen, C. B. \& Chang, C. W. (2002). Screening Synchronously Occurred Multiple Abnormal Quality Characteristics Screening in a Silicon Wafer Slicing Process, The Asian Journal on Quality, Vol., 3, No., 1, pp.4860, ISSN: 1598-2688.

Lin, Z. C. \& Lin, W. S. (2001). The Application of Grey Theory to the Prediction of Measurement Points for Circularity Geometric Tolerance, The International Journal of Advanced Manufacturing Technology, Vol., 17, No., 5, pp. 348-360, ISSN: 0268-3768 (Paper) 1433-3015 (Online).

Lucas, J. M. \& Saccussi, M. S. (1992) Exponentially Weighted Moving Average Control Charts: Properties and Enhancements, Technometrics, Vol., 24, pp. 
216-231, ISSN: 0040-1706.

Morgan, D. L. (1997). The Focus Groups Guidebook, Focus Group Kit 1, Sage Publications, Thousand Oaks, ISBN: 0761908188.

Robert, S. (1959). Control Chart Tests Based on Geometric Moving Averages, Technometrics, Vol., 1, pp. 239-250, ISSN: 0040-1706.

Takeshi, H. (1998). Ultraclean Surface Processing of Silicon Wafers: Secrets of VLSI Manufacturing, Springer, ISBN: 3540616721. 


\section{Manufacturing}

the Future

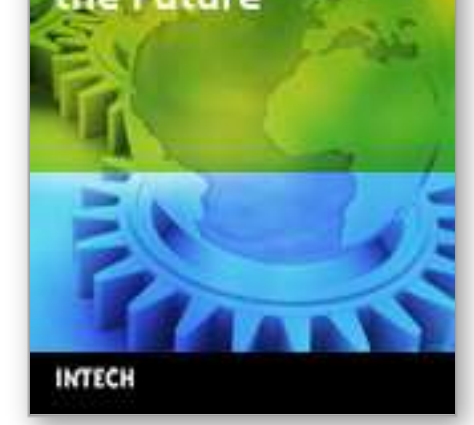

\section{Manufacturing the Future}

Edited by Vedran Kordic, Aleksandar Lazinica and Munir Merdan

ISBN 3-86611-198-3

Hard cover, 908 pages

Publisher Pro Literatur Verlag, Germany / ARS, Austria

Published online 01, July, 2006

Published in print edition July, 2006

The primary goal of this book is to cover the state-of-the-art development and future directions in modern manufacturing systems. This interdisciplinary and comprehensive volume, consisting of 30 chapters, covers a survey of trends in distributed manufacturing, modern manufacturing equipment, product design process, rapid prototyping, quality assurance, from technological and organisational point of view and aspects of supply chain management.

\section{How to reference}

In order to correctly reference this scholarly work, feel free to copy and paste the following:

Che-Wei Chang (2006). Relative Control and Management Philosophy, Manufacturing the Future, Vedran Kordic, Aleksandar Lazinica and Munir Merdan (Ed.), ISBN: 3-86611-198-3, InTech, Available from: http://www.intechopen.com/books/manufacturing_the_future/relative_control_and_management_philosophy

\section{INTECH}

open science | open minds

\section{InTech Europe}

University Campus STeP Ri

Slavka Krautzeka 83/A

51000 Rijeka, Croatia

Phone: +385 (51) 770447

Fax: +385 (51) 686166

www.intechopen.com

\author{
InTech China \\ Unit 405, Office Block, Hotel Equatorial Shanghai \\ No.65, Yan An Road (West), Shanghai, 200040, China \\ 中国上海市延安西路65号上海国际贵都大饭店办公楼 405 单元 \\ Phone: +86-21-62489820 \\ Fax: $+86-21-62489821$
}


(C) 2006 The Author(s). Licensee IntechOpen. This chapter is distributed under the terms of the Creative Commons Attribution-NonCommercial-ShareAlike-3.0 License, which permits use, distribution and reproduction for non-commercial purposes, provided the original is properly cited and derivative works building on this content are distributed under the same license. 